\title{
Goals for rheumatoid arthritis: treating to target or treating to prevent?
}

This article was published in the following Dove Press journal:

Open Access Rheumatology: Research and Reviews

9 July 2012

Number of times this article has been viewed

\section{Min Yang \\ Mingyang Guo \\ Rheumatology Center, PLA General Hospital of Chengdu Military Area Command, Chengdu, Sichuan Province, PR China}

\begin{abstract}
Although treat-to-target goals for rheumatoid arthritis (RA) have been well-established through several guidelines in recent years, concerns regarding treat-to-prevent goals for RA remain unclear. RA patients are typically subjected to over- or under-treatment because it is difficult for clinicians to determine the prognosis of RA patients. This typically results in failure to select and identify patient subsets that should receive monotherapy or combination therapy to treat early RA. Understanding treat-to-prevent goals, as well as unfavorable prognoses, risk factors, and prediction methods for RA, is therefore critical for making treatment decisions. Rapid radiographic progression plays a central role in contributing to other composite RA indices, so this may be the best method for defining treat-to-prevent goals for RA. Accordingly, risk factors of rapid radiographic progression have been defined and two prediction models were retrospectively derived based on clinical trial data. Additional studies are required to develop risk models that can be used for accurate predictions.
\end{abstract}

Keywords: rapid radiographic progression, prognosis, risk factors, prediction models

\section{Introduction}

Doctors experience significant difficulty in choosing between monotherapy and combination therapy for treating early rheumatoid arthritis (RA) patients. Several studies have suggested that combination therapy with conventional disease-modifying antirheumatic drugs (DMARDs) and novel biologic agents may be effective during early stages of the disease and may influence the long-term prognosis; however, some early RA patients may achieve clinical remission through the use of a single DMARD. ${ }^{1,2}$ Accordingly, this subset of RA patients may be over-treated with the use of combination DMARDs, while other patients may achieve poor treatment response with a single drug. Therefore, selecting and identifying patient subsets to receive monotherapy or combination therapy is critical for properly treating early RA. During the 75th Annual Scientific Meeting of the American College of Rheumatology (ACR), several concerns regarding the 2012 ACR recommendations for treating RA were discussed. Similar to the 2008 ACR recommendations, ${ }^{3}$ prognostic assessment of RA was emphasized as a necessary precondition for treatment decisions. The use of monotherapy or combination therapy should be recommended depending upon predictions to determine whether RA patients have a favorable or unfavorable prognosis.

Thus, guidelines should be set that can be used to determine whether the prognosis is favorable or unfavorable. Currently, no guidelines exist to differentiate between poor outcomes and good outcomes for RA treatment. ${ }^{4}$ Although various clinical composite indices such as the disease activity score, disease activity score in 28 joints, simplified 
disease activity index (SDAI), clinical disease activity index, health assessment questionnaire, modified health assessment questionnaire, multidimensional health assessment questionnaire, and routine assessment of patient index data, are widely used in clinical practice, these indices are often only useful for evaluating disease activity but not for describing treatment outcomes. ${ }^{5}$

Additionally, risk factors for poor treatment outcomes are not well-defined. Various environment, patient, and diseaseassociated predictive factors have been proposed for both early and late RA, but their usefulness in guiding treatment choices at the individual level remains unclear. It remains difficult for rheumatology doctors to translate predictions into treatment choices for individual patients recently diagnosed with RA. Additional concerns include effective prediction of treatment outcomes, the usefulness of risk factors, and making treatment decisions based on currently existing evidence. The answers to these questions remain unclear.

\section{Treat-to-target goals versus treat-to-prevent goals}

Generally, a good outcome for a disease is considered total recovery or clinical remission. Since total recovery from RA is not possible, clinical remission is considered a good outcome or a treat-to-target goal. ${ }^{6}$ Threshold score for clinical remission were clearly defined in the disease activity score $(<1.6)$, disease activity score in 28 joints $(<2.6)$, SDAI $(<3.3)$, clinical disease activity index $(<2.8)$, health assessment questionnaire $(\leq 0.5)$, modified health assessment questionnaire $(\leq 3.0)$, multidimensional health assessment questionnaire $(\leq 3.0)$, and routine assessment of patient index data ( $\leq 3.0) .{ }^{5,7}$ Furthermore, recently published recommendations established by the ACR and the European League Against Rheumatism define clinical remission of RA as tender joint count, swollen joint count (SJC), C-reactive protein (CRP, $\mathrm{mg} / \mathrm{dL}$ ), and patient global assessment (on a 0-10 scale) all of $\leq 1$ or and SDAI of $\leq 3.3 .^{8}$ These definitions are clinically practicable and widely accepted as treat-to-target goals for RA; however, definitions of poor treatment outcomes or treat-to-prevent goals are vague. Though low, moderate, and high disease activity have been described in some of these composite indices, these activities may not be appropriate for use as prevention goals. Treatment of RA guided by these composite indices is not sufficient for achieving clinical and radiological remission. ${ }^{9}$ Furthermore, varying levels of disease activity may not necessarily be a poor treatment outcome for RA. For example, moderate RA activity may be considered a treatment failure if baseline disease activity was low, while treatment may be defined as successful if baseline RA activity was high. Contradictions arise for these multichotomous dependent variables because disease states are described at single time points while disease changes are not described. Thus, treatment outcome should be defined in reference to the level of improvement or deterioration. ACR response criteria (ACR 20, ACR 50, and ACR 70), another composite index, describe the percentage of disease improvement and compare disease activity at two discrete time points; however, these criteria are used to discriminate effective treatment from placebo treatment based on clinical trial data and are not directly applicable to clinical practice. ${ }^{10}$

Thus, treat-to-prevent goal of early RA must be defined. Additionally, disease conditions that should actively be prevented may include death, systemic features, pains, red swelling, joint deformation, and limb disability. Because RA itself is not a fatal disease, it is not reasonable to define treatto-prevent goals of early RA as death. In clinical practice, prevention of death is not considered a primary goal when treating RA. Moreover, reduction of pain, red swelling, or systemic features does not necessarily indicate the disease has been effectively controlled.

From a clinical perspective, joint deformation, ankylosis, and limb disability are unfavorable outcomes for most early

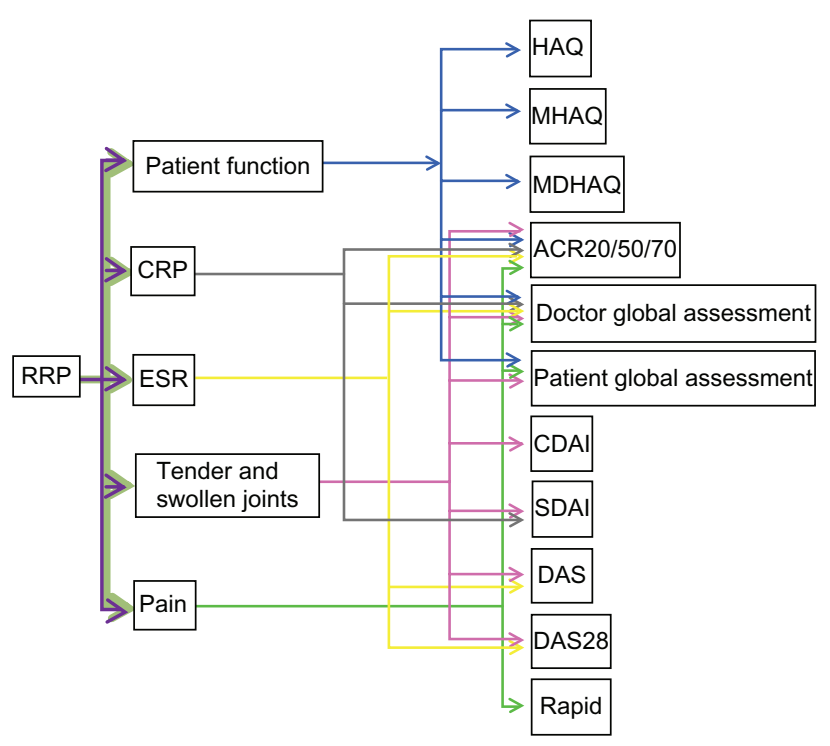

Figure I RRP plays a centre role in contributing to other composite RA indices. Because of bone and cartilage erosion and destruction, RRP usually causes severe pains, joint tenderness, swelling, elevated CRP titer and ESR, which weigh heavily in determining several indices of RA, like ACR response criteria, DAS and DAS28, CDAI, SDAI, HAQ and MHAQ, RAPID and MDHAQ.

Abbreviations: RRP, rapid radiographic progression; RA, rheumatoid arthritis; CRP, $C$ response protein; ESR, erythrocyte sedimentation rate; ACR, American College of Rheumatology; SJC, swollen joint count; CDAl, clinical disease activity index; SDAl, simplified disease activity index; HAQ, health health assessment questionnaire; MHAQ, modified health assessment questionnaire; MDHAQ, multidimensional health assessment questionnaire; RAPID, routine assessment of patient index data. 
RA patients not receiving drugs or in those receiving DMARD monotherapy. The pathological nature of lesions involving bone and cartilage erosion and destruction eventually results in joint narrowing and fusion. ${ }^{4}$ Iconography is a descriptive method used to record these pathological changes. ${ }^{11}$ The Sharp/van der Heijde score (SHS), an iconography rating system, was shown to be closely associated with joint deformation and limb disability; and over a period of time (typically 1 year), a rapid increase in the SHS predicts a high probability of disability. ${ }^{12}$ Accordingly, a novel index, rapid radiographic progression (RRP), was defined as $\mathrm{SHS} \geq 5 \mathrm{U} / 1$ year. ${ }^{13} \mathrm{RRP}$ is typically accompanied by severe pain, joint swelling and tenderness, high titer CRP and elevated erythrocyte sedimentation rate (ESR), which contribute significantly to RA composite indices (Figure 1). Therefore, RRP plays a central role in contributing to other composite RA indices.

In clinical practice, RRP typically occurs in a minority of treated patients; effective therapy in these patients can reduce the odds of progression by up to $78 \%$. Furthermore, early and intensive treatment can slow the rate of radiographic progression. ${ }^{14}$ Identifying individual RA patients at high risk for RRP is therefore critical to making appropriate treatment choices. ${ }^{13}$ RRP directly indicates a poor outcome for RA patients; thus, it may be the most appropriate marker for defining treat-to-prevent goals for RA.

\section{Risk factors for RRP}

Previous studies have indicated that several conditions are associated with unfavorable prognosis of RA (Table 1). Human leukocyte antigen-DRB $1^{15-17}$ and protein tyrosine phosphatase nonreceptor 22 genes, ${ }^{18-20}$ anti-citrullinated protein antibodies (ACPA), ${ }^{21-27} \mathrm{ESR},{ }^{28,29} \mathrm{CRP},{ }^{30,31}$ rheumatoid factor (RF), ${ }^{32}$ and erosion score ${ }^{33}$ are well-established risk factors associated with an unfavorable prognosis of RA, while other conditions, such as smoking, ${ }^{34-36}$ female sex, ${ }^{37-39}$ old age, ${ }^{40,41}$ psychological factors,${ }^{42}$ and low level of formal education ${ }^{43}$ show inconsistent associations with RA prognosis. Clearly, the definition of an unfavorable prognosis is vague and therefore cannot be interpreted as RRP. Thus, whether these conditions are associated with RRP is unknown.

With the data from an active-controlled study known as Patients Receiving Infliximab (IFX) for the Treatment of RA of Early Onset performed by St Clair et al, ${ }^{13}$ this question was partially answered. This double-blind study involved 1049 early RA patients randomly assigned to receive methotrexate (MTX) monotherapy or MTX in combination with IFX over 46 weeks to establish a correlation between RRP and baseline risk factors, including CRP, ESR, SJC, and RF. In these 1049 patients, high titer CRP, RF, and high ESR and SJC are typically suggestive of a high percentage of RRP. Another study reported a similar correlation between CRP, RF, ACPA, erosion score, and RRP. ${ }^{48}$ In these two studies CRP, ESR, RF, SJC, ACPA, erosion score, and treatment methods were considered baseline risk factors for predicting the potential for RRP. Additionally, different treatment (monotherapy of MTX and combination therapy of MTX plus IFX) significantly influenced RRP rate. Conservative treatment (monotherapy) typically resulted in a higher RRP rate, while aggressive treatment (combination therapy) remarkably decreased RRP rate. A close correlation between clearly defined risk factors and clearly defined poor outcomes for RA was established. Developing a method for prognostic prediction of RA is now possible.

\section{Risk models}

One risk model was derived based on trichotomous variables, including CRP $(<0.6,0.6-3$ or $>3 \mathrm{mg} / \mathrm{dL})$, ESR $(<21$, $21-50$ or $>50 \mathrm{~mm} / \mathrm{h})$, RF $(<80,80-200$ or $>200 \mathrm{U} / \mathrm{mL})$, SJC $(<10,10-17$ or $>17)$, and treatment method. ${ }^{13}$ These variables of different levels define a series of subgroups in the 1049 early RA patients. RRP rate in each subgroup reveals the likelihood of RRP in an RA in this subgroup. A similar model derived by Visser et al was based on CRP, RF, ACPA, and erosion score. ${ }^{48}$ This risk model was established based on data from a smaller population of 465 RA patients. Clearly in both risk models, the number of subjects in each subgroup is not sufficient to achieve a representative RRP rate. Additionally, CRP level in both models is significantly different, suggesting a large difference between these two early RA populations. Therefore, larger studies need to be conducted to obtain epidemiological data from early RA patients under monotherapy or combination therapy; this will help to establish a more powerful risk model for predicting RA outcomes.

\section{Conclusion}

The cause of RA is unknown and the prognosis is not easy to predict. Although several composite indices have been welldefined for predicting a good prognosis, treat-to-target goals for RA, the definition, and risk factors for poor prognosis are unclear. RRP plays a central role in contributing to most composite RA indices and directly reflects poor outcomes of RA; Thus, RRP may be the most suitable marker for defining the treat-to-prevent goals. Identifying individual RA patients 


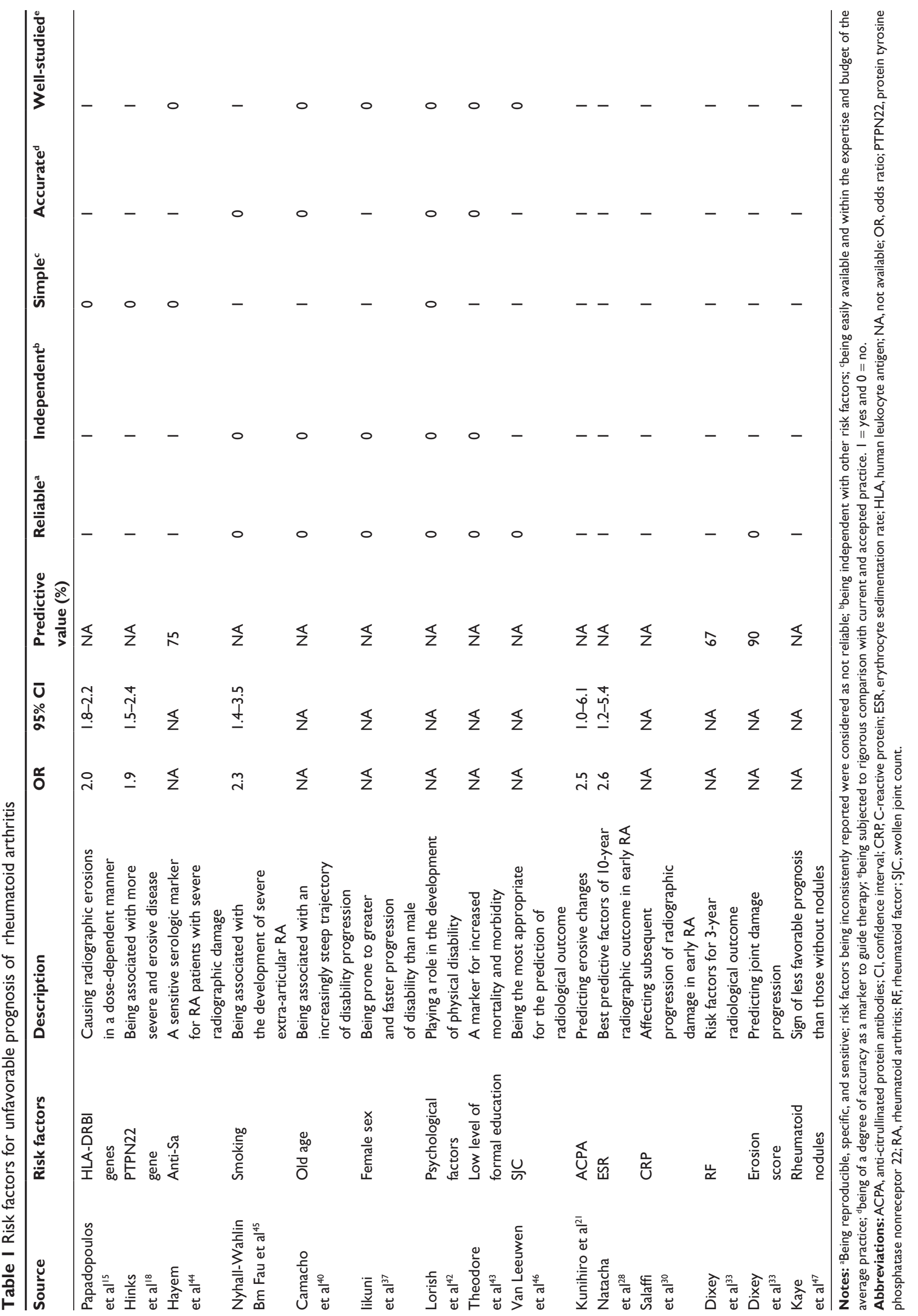


at a high risk of RRP is therefore critical to making appropriate treatment decisions. Several risk factors have been described to be closely associated with RRP. Some risk models use these risk factors to predict the probability of RRP; however, these risk models were developed retrospectively. Therefore, additional studies are necessary to develop more powerful risk models.

\section{Disclosure}

The author reports no conflicts of interest in this work.

\section{References}

1. Kuriya B, Arkema EV, Bykerk VP, Keystone EC. Efficacy of initial methotrexate monotherapy versus combination therapy with a biological agent in early rheumatoid arthritis: a meta-analysis of clinical and radiographic remission. Ann Rheum Dis. 2010;69(7):1298-1304.

2. Allaart CF, Huizinga TW. Treatment strategies in recent onset rheumatoid arthritis. Curr Opin Rheumatol. 2011;23(3):241-244.

3. Saag KG, Teng GG, Patkar NM, et al. American College of Rheumatology 2008 recommendations for the use of nonbiologic and biologic disease-modifying antirheumatic drugs in rheumatoid arthritis. Arthritis Rheum. 2008;59(6):762-784.

4. McInnes IB, Schett G. The pathogenesis of rheumatoid arthritis. NEngl J Med. 2011;365(23):2205-2219.

5. Sokka T. How should rheumatoid arthritis disease activity be measured today and in the future in clinical care? Rheum Dis Clin North Am. 2010;36(2):243-257.

6. Jayakumar K, Norton S, Dixey J, et al. Sustained clinical remission in rheumatoid arthritis: prevalence and prognostic factors in an inception cohort of patients treated with conventional DMARDS. Rheumatology (Oxford). 2012;51(1):169-175.

7. van Tuyl LH, Felson DT, Wells G, Smolen J, Zhang B, Boers M. Evidence for predictive validity of remission on long-term outcome in rheumatoid arthritis: a systematic review. Arthritis Care Res (Hoboken). 2010;62(1):108-117.

8. Iking-Konert C, Aringer M, Wollenhaupt J, et al. Performance of the new $2011 \mathrm{ACR} / \mathrm{EULAR}$ remission criteria with tocilizumab using the phase IIIb study TAMARA as an example and their comparison with traditional remission criteria. Ann Rheum Dis. 2011;70(11):1986-1990.

9. Rezaei H, Saevarsdottir S, Forslind K, et al. In early rheumatoid arthritis, patients with a good initial response to methotrexate have excellent 2-year clinical outcomes, but radiological progression is not fully prevented: data from the methotrexate responders population in the SWEFOT trial. Ann Rheum Dis. 2012;71(2):186-191.

10. Ranganath VK, Khanna D, Paulus HE. ACR remission criteria and response criteria. Clin Exp Rheumatol. 2006;24(6 Suppl 43): S-14-21.

11. Yang M, Xiao C, Wu Q, et al. Anti-inflammatory effect of Sanshuibaihu decoction may be associated with nuclear factor-kappa B and p38 MAPK alpha in collagen-induced arthritis in rat. $J$ Ethnopharmacol. 2010;127(2):264-273.

12. van den Broek, M. D, L. D, et al. Rapid radiological progression in the first year of rheumatoid arthritis predicts both disability and radiological joint damage progression over 8 years of targeted treatment. Arthritis Rheum. 2011;63(Suppl 10):418.

13. Vastesaeger N, Xu S, Aletaha D, St Clair EW, Smolen JS. A pilot risk model for the prediction of rapid radiographic progression in rheumatoid arthritis. Rheumatology (Oxford). 2009;48(9):1114-1121.

14. Kyburz D, Gabay C, Michel BA, Finckh A. The long-term impact of early treatment of rheumatoid arthritis on radiographic progression: a population-based cohort study. Rheumatology (Oxford). 2011;50(6):1106-1110.
15. Gorman JD, Lum RF, Chen JJ, Suarez-Almazor ME, Thomson G, Criswell LA. Impact of shared epitope genotype and ethnicity on erosive disease: a meta-analysis of 3,240 rheumatoid arthritis patients. Arthritis Rheum. 2004;50(2):400-412.

16. Delgado-Vega AM, Anaya JM. Meta-analysis of HLA-DRB1 polymorphism in Latin American patients with rheumatoid arthritis. Autoimmun Rev. 2007;6(6):402-408.

17. Vos K, Visser H, Schreuder GMT, et al. Human leukocyte antigen-DQ and DR polymorphisms predict rheumatoid arthritis outcome better than DR alone. Hum Immunol. 2001;62(11):1217-1225.

18. Hinks A, Barton A, John S, et al. Association between the PTPN22 gene and rheumatoid arthritis and juvenile idiopathic arthritis in a UK population: further support that PTPN22 is an autoimmunity gene. Arthritis Rheum. 2005;52(6):1694-1699.

19. Begovich AB, Carlton VEH, Honigberg LA, et al. A missense singlenucleotide polymorphism in a gene encoding a protein tyrosine phosphatase (PTPN22) is associated with rheumatoid arthritis. Am J Hum Genet. 2004;75(2):330-337.

20. Gregersen PK. Pathways to gene identification in rheumatoid arthritis: PTPN22 and beyond. Immunol Rev. 2005;204(1):74-86.

21. Nishimura K, Sugiyama D, Kogata Y, et al. Meta-analysis: diagnostic accuracy of anti-cyclic citrullinated peptide antibody and rheumatoid factor for rheumatoid arthritis. Ann Intern Med. 2007;146(11):797-808.

22. Emad Y, Shehata M, Ragab Y, Saad A, Hamza H, Abou-Zeid A. Prevalence and predictive value of anti-cyclic citrullinated protein antibodies for future development of rheumatoid arthritis in early undifferentiated arthritis. Mod Rheumatol. 2010;20(4):358-365.

23. Avouac J, Gossec L, Dougados M. Diagnostic and predictive value of anti-cyclic citrullinated protein antibodies in rheumatoid arthritis: a systematic literature review. Ann Rheum Dis. 2006;65(7):845-851.

24. van Venrooij WJ, Zendman AJ, Pruijn GJ. Autoantibodies to citrullinated antigens in (early) rheumatoid arthritis. Autoimmun Rev. 2006;6(1):37-41.

25. Zendman AJ, Vossenaar ER, van Venrooij WJ. Autoantibodies to citrullinated (poly)peptides: a key diagnostic and prognostic marker for rheumatoid arthritis. Autoimmunity. 2004;37(4):295-299.

26. Bukhari M, Thomson W, Naseem H, Bunn D, et al. The performance of anti-cyclic citrullinated peptide antibodies in predicting the severity of radiologic damage in inflammatory polyarthritis: results from the Norfolk Arthritis Register. Arthritis Rheum. 2007;56(9):2929-2935.

27. Meyer O, Labarre C, Dougados M, et al. Anticitrullinated protein/ peptide antibody assays in early rheumatoid arthritis for predicting five year radiographic damage. Ann Rheum Dis. 2003;62(2):120-126.

28. Courvoisier N, Dougados M, Cantagrel A, et al. Prognostic factors of 10-year radiographic outcome in early rheumatoid arthritis: a prospective study. Arthritis Res Ther. 2008;10(5):R106.

29. Silva I, Mateus M, Branco JC. Assessment of erythrocyte sedimentation rate (ESR) and C-reactive protein (CRP) on rheumatoid arthritis activity prediction. Acta Reumatol Port. 2010;35(5):456-462.

30. Salaffi F, Carotti M, Ciapetti A, Gasparini S, Filippucci E, Grassi W. Relationship between time-integrated disease activity estimated by DAS28-CRP and radiographic progression of anatomical damage in patients with early rheumatoid arthritis. BMC Musculoskelet Disord. 2011;12:120.

31. Pope JE, Thorne C, Haraoui BP, Truong D, Psaradellis E, Sampalis JS. Does C-reactive protein add value in active rheumatoid arthritis? Results from the Optimization of Humira Trial. Scand J Rheumatol. 2011;40(3):232-233.

32. Ibn Yacoub Y, Amine B, Laatiris A, Hajjaj-Hassouni N. Rheumatoid factor and antibodies against citrullinated peptides in Moroccan patients with rheumatoid arthritis: association with disease parameters and quality of life. Clin Rheumatol. 2012;31(2):329-334.

33. Dixey J, Solymossy C, Young A. Is it possible to predict radiological damage in early rheumatoid arthritis (RA)? A report on the occurrence, progression, and prognostic factors of radiological erosions over the first 3 years in 866 patients from the Early RA Study (ERAS). J Rheumatol Suppl. 2004;69:48-54. 
34. Papadopoulos NG, Alamanos Y, Voulgari PV, Epagelis EK, Tsifetaki N, Drosos AA. Does cigarette smoking influence disease expression, activity and severity in early rheumatoid arthritis patients? Clin Exp Rheumatol. 2005;23(6):861-866.

35. Mikuls TR, Hughes LB, Westfall AO, et al. Cigarette smoking, disease severity and autoantibody expression in African Americans with recentonset rheumatoid arthritis. Ann Rheum Dis. 2008;67(11):1529-1534.

36. Finckh A, Dehler S, Costenbader KH, Gabay C. Cigarette smoking and radiographic progression in rheumatoid arthritis. Ann Rheum Dis. 2007;66(8):1066-1071.

37. Iikuni N, Sato E, Hoshi M, et al. The influence of sex on patients with rheumatoid arthritis in a large observational cohort. J Rheumatol. 2009;36(3):508-511.

38. Sokka T, Toloza S, Cutolo M, et al. Women, men, and rheumatoid arthritis: analyses of disease activity, disease characteristics, and treatments in the QUEST-RA study. Arthritis Res Ther. 2009;11(1):R7.

39. Merlino LA, Cerhan JR, Criswell LA, Mikuls TR, Saag KG. Estrogen and other female reproductive risk factors are not strongly associated with the development of rheumatoid arthritis in elderly women. Semin Arthritis Rheum. 2003;33(2):72-82.

40. Camacho EM, Verstappen SM, Lunt M, Bunn DK, Symmons DP. Influence of age and sex on functional outcome over time in a cohort of patients with recent-onset inflammatory polyarthritis: results from the Norfolk Arthritis Register. Arthritis Care Res (Hoboken). 2011;63(12):1745-1752.

41. Amador-Patarroyo MJ, Rodriguez-Rodriguez A, Montoya-Ortiz G. How does age at onset influence the outcome of autoimmune diseases? Autoimmune Dis. 2012;2012:251730.
42. Lorish CD, Abraham N, Austin J, Bradley LA, Alarcon GS. Disease and psychosocial factors related to physical functioning in rheumatoid arthritis. J Rheumatol. 1991;18(8):1150-1157.

43. Pincus T, Callahan LF. Formal education as a marker for increased mortality and morbidity in rheumatoid arthritis. J Chronic Dis. 1985;38(12):973-984.

44. Hayem G, Chazerain P, Combe B, et al. Anti-Sa antibody is an accurate diagnostic and prognostic marker in adult rheumatoid arthritis. J Rheumatol. 1999;26(1):7-13.

45. Nyhall-Wahlin BM, Petersson IF, Nilsson JA, Jacobsson LT, Turesson C. High disease activity disability burden and smoking predict severe extraarticular manifestations in early rheumatoid arthritis. Rheumatology (Oxford). 2009;48(4):416-420.

46. van Leeuwen MA, van der Heijde DM, van Rijswijk MH, et al. Interrelationship of outcome measures and process variables in early rheumatoid arthritis. A comparison of radiologic damage, physical disability, joint counts, and acute phase reactants. J Rheumatol. 1994;21(3): 425-429.

47. Kaye BR, Kaye RL, Bobrove A. Rheumatoid nodules. Review of the spectrum of associated conditions and proposal of a new classification, with a report of four seronegative cases. Am J Med. 1984;76(2):279-292.

48. Visser K, Goekoop-Ruiterman YP, de Vries-Bouwstra JK, et al. A matrix risk model for the prediction of rapid radiographic progression in patients with rheumatoid arthritis receiving different dynamic treatment strategies: post hoc analyses from the BeSt study. Ann Rheum Dis. 2010;69(7):1333-1337.
Open Access Rheumatology Research and Reviews

\section{Publish your work in this journal}

Open Access Rheumatology Research and Reviews is an international, peer-reviewed, open access journal, publishing all aspects of clinical and experimental rheumatology in the clinic and laboratory including the following topics: Pathology, pathophysiology of rheumatological diseases; Investigation, treatment and management of rheumatological

\section{Dovepress}

diseases; Clinical trials and novel pharmacological approaches for the treatment of rheumatological disorders. The manuscript management system is completely online and includes a very quick and fair peerreview system, which is all easy to use. Visit http://www.dovepress.com/ testimonials.php to read real quotes from published authors. 